\title{
Letters
}

Website: bmj.com

Email: letters@bmj.com

\section{NHS league tables are more spin than substance}

EDITOR-My hospital was last month awarded the coveted top ranking of three stars in the NHS league table.

The kidney unit in which I work has 65 patients on the waiting list to start dialysis for kidney failure. Ten dialysis stations lie empty, which could accomodate all of them if the revenue was forthcoming, which it hasn't been for many many months. Only when someone dies or receives a transplant will a space become available. This state of affairs does not exist anywhere in Europe, even in Bulgaria-one of Europe's poorest countries.

Several patients require parathryroidectomy for secondary hyperparathyroism, a well known complication of chronic renal failure. It takes 3-4 months to see the overstretched surgeon and a further 9-12 months before he can do the operation. The patients are put on a "pre-list list" and after 3-4 months are contacted to find out when in the next 6-9 months they would like to have the operation. This is called patients' choice in selecting the date.

On that date they have to first ring the hospital to find out if a bed is available. Not uncommonly there is no bed because of overspill from the medical wards on to the

\section{Advice to authors}

We prefer to receive all responses electronically, sent directly to our website. Processing your letter will be delayed unless it arrives in an electronic form.

We are now posting all direct submissions to our website within 24 hours of receipt and our intention is to post all other electronic submissions there as well. All responses will be eligible for publication in the paper journal.

Responses should be under 400 words and relate to articles published in the preceding month. They should include $\leqslant 5$ references, in the Vancouver style, including one to the BMJ article to which they relate. We welcome illustrations.

Please supply each author's current appointment and full address, and a phone or fax number or email address for the corresponding author. We ask authors to declare any competing interest. Please send a stamped addressed envelope if you would like to know whether your letter has been accepted or rejected.

Letters will be edited and may be shortened.

bmj.com

letters@bmj.com surgical wards, as in winter bed crises, and the operation is postponed for weeks or months. A colleague in Belgium tells me the waiting time to see a surgeon and have this type of operation is two weeks there. The United Kingdom is one of the seven richest nations in the world.

These are but two examples from just one unit in a hospital that has gained the highest award of three stars. I shudder to think what it must be like in hospitals with two stars or one star or even none.

The NHS as it is currently structured, financed, and managed, with its politically oriented objectives, has failed the public who use it and the health professionals who work in it

Colin B Brown consultant renal physician Sheffield Kidney Institute, Northern General Hospital, Sheffield S5 7AU

cbbrown1@compuserve.com

1 Klein R. Mr Milburn's good hospital guide. BMJ 2002;325:230-1. (3 August.)

\section{Barriers to effective stroke care out of hours need to be broached}

EDITOR-The article by Harraf et al is a welcome addition to much needed hard data on the poor delivery of evidence based and patient focused care in the United Kingdom. ${ }^{1}$ The paper prompts the need to analyse prospectively the nature of the barriers to timely assessment, investigation, and treatment of a patient presenting with a potentially life threatening stroke.

The paper would have benefited from providing readers with the subset analysis of time to assessment, senior opinion, and computed tomography in the 128 hours of the week $(76 \%)$ that fall outside 9 am- 5 pm Monday-Friday.

In a typical emergency department $66 \%$ of patients arrive outside these normal working hours. The authors say that $28 \%$ arrive after 1759 and before 0600 , and state in their abstract that "time of presentation did not influence time to evaluation by senior [non-emergency] doctor," but they do not provide results to support this.

In many departments in which I have worked previously, I have noticed a recurring pattern of barriers for emergency department staff to overcome to obtain rapid computed tomography of the head after 5 pm Monday-Friday.

(1) Scan radiographer asks: "Have you phoned the radiologist at home?"

(2) Radiologist then asks: "Has the admitting medical team seen and assessed the patient?"

(3) Radiologist then asks: "Has someone from the middle grade medical team assessed the patient?"

(4) Radiologist then says: "Get the admitting medical team to phone me, as they will be acting on the results, not you.'

(5) The senior house officer in the emergency department bleeps the medical senior house officer twice before getting the response: "I'm still in the medical assessment unit seeing three other patients first."

The staff in emergency departments thus realise that for a quiet life it is easier to simply write in the notes: "CVA [cerebrovascular accident] - refer medics" and return to the queue of triage category 4 and 5 patients.

What hope is there then of using an as yet unlicensed drug for thrombolysis in patients with stroke? It is difficult to obtain funding and staffing for thrombolysis for myocardial infarction in an emergency department, the one hospital department that is obliged to provide timely assessment and investigation of and resuscitation for life threatening conditions.

The paper by Harraf et al should change clinicians' approach to stroke, but this is not going to happen while national guidance is issued by a working party without a representative of the Faculty of Accident and Emergency Medicine or the Royal College of Radiologists. ${ }^{2}$

Mark F Nicol specialist/locum consultant

Macclesfield SK10 3BL

markfnicol@hotmail.com

1 Harraf F, Sharma AK, Brown M, Lees KR, Vass RI, Kalra I. A multicentre observational study of presentation an assessment of acute stroke. BMJ 2002:325:17-20. (6 July.) 2 Intercollegiate Working Party on Stroke. Natiomal clinical guidelines on stroke. London: Royal College of Physicians, 2000.

\section{Cases of congenital rubella may be the tip of the iceberg}

EDITOR-We have diagnosed congenital rubella infection in another infant since publication of our two other cases as a lesson of the week. ${ }^{1}$

The infant was born to a Sri Lankan primiparous woman who had lived in the 
United Kingdom for six years and had not travelled abroad in the recent past or had contact with rubella. The mother was susceptible to rubella on routine antenatal testing at 12 weeks' gestation. The infant was born at 34 weeks' gestation with intrauterine growth restriction and thrombocytopenia but no other serious sequelae.

The infant and mother both tested positive for rubella IgM. The mother gave a clear history of a transient, non-itchy rash at 26 weeks' gestation. We could not find any social or community link between this mother and those in our two previous cases.

Rubella is highly infectious. In a recent case report from another London hospital rubella virus was nosocomially acquired by an infant being cared for in the same neonatal nursery as an infant with the congenital rubella syndrome. ${ }^{2}$ As we know that at least three infants are excreting rubella virus in north west London, we now test for rubella IgM in all infants with severe intrauterine growth restriction (birth weight $<$ 3rd centile).

We believe that rubella infection may be underdiagnosed, given the recent decline in uptake of measles, mumps, and rubella (MMR) vaccination and the existence of at least five cases of congenital rubella infection in areas of London with large numbers of immigrant women from countries where rubella is endemic and childhood vaccination is not routine. A review of antenatal screening data from maternity units in north London showed that $23 \%$ of primiparous women of Sri Lankan origin were susceptible to rubella on routine antenatal screening testing in 1996-9 ( $\mathrm{P}$ Tookey, personal communication).

A high index of suspicion and appropriate investigation of any suspicious rash in pregnancy are needed if the devastating effects of the congenital rubella syndrome are to be prevented from again becoming widespread in the United Kingdom. Clear guidelines on the management of, and exposure to, rash in pregnancy are contained in a report fom a working party of the Public Health Laboratory Service. ${ }^{3}$

Primary healthcare workers and midwives need to be aware of the need for targeted immunisation before pregnancy and for extra vigilance, particularly in women of childbearing age who have recently arrived from countries where rubella is endemic.

Roslyn M Thomas consultant paediatrician Nilesh M Mehta specialist registrar, neomatal intensive care unit

Northwick Park Hospital, Harrow HA1 3UJ ros.thomas@nwlh.nhs.uk

Mehta NM, Thomas RM. Antenatal screening for rubellainfection or immunity? BMJ 2002;325:90-1. (13 July.)

2 Sheridan E, Aitken C, Jeffries D, Hird M, Thayalasekaran P. Congenital rubella syndrome: a risk in immigrant populations. Lancet 2002;359:674-5.

3 Morgan-Capner P, Crowcroft N. Guidance on the management of, and exposure to, rash illness in pregnancy (including consideration of the relevant antibody soreening programmes in pregrancy. Report of a Public Health Laboto Serith Laboratory Services working group. London: PHLS, 2000.

\section{Aspects of MMR}

Survey shows that some homoeopaths and chiropractors advise against MMR

EDITOR-Vaccination for measles, mumps, and rubella (MMR) is highly controversial. One of us (EE) found that some providers of complementary medicine have a negative attitude towards immunisation. ${ }^{2}$ We therefore evaluated and compared the response of professional homoeopaths, chiropractors, and general practitioners to an inquiry about MMR vaccination.

We obtained the email addresses of the three health professions from these websites: www.homeopath.co.uk/directory, www.chiroonline.com/interadcom, www.internetgp. com/gpsites/alphabethtm. We also visited the private homepages of homoeopaths and chiropractors on the internet. We sent a letter in which a mother asked for advice about the MMR vaccination for her 1 year old child to all the addresses. We explained to all those who responded that the query was, in fact, part of a research project, giving them opportunity to withdraw their answers. The study was approved by the local ethics committee.

We contacted 168 homoeopaths, of whom $104(72 \%)$ responded, 27 (26\%) withdrawing their answers. We contacted 63 chiropractors, of whom $22(44 \%)$ responded, six $(27 \%)$ withdrawing their responses. No general practitioners responded. The table shows that only a few professional homoeopaths and a quarter of the chiropractors advised in favour of the MMR vaccination. Almost half of the homoeopaths and nearly a fifth of the chiropractors advised against it.

These data suggest that some providers of complementary medicine are advising people against government policy. General practitioners, on the other hand, seem not respond at all to patients' emails on this delicate matter.

\section{K Schmidt Pilkington research fellow}

\section{E Ernst director}

Department of Complementary Medicine, University of Exeter, Exeter EX2 4NT

1 Ferriman A. London mayor attacked for doing "irreparable damage" on MMR. BMJ 2002;325:66. (13 July.)

2 Ernst E. Rise in popularity of complementary and alternative medicine: reasons and consequences for vaccination Vaccine 2002;20:S90-3

\section{Trying to find biological cause for autism} does not make sense

EdiToR-Can vaccines cause autism? ${ }^{1}$ Not really. Autism has no actual physical form; it is identified and diagnosed behaviourally, and most medical practitioners do not possess psychological competence. I am therefore not sure that something like autism is entirely contained in the medical sphere. I am a social psychologist and therefore interested in human interaction and its effects on behaviour. I am autistic myself and was not immunised with the measles, mumps, and rubella (MMR) vaccine.

Kurt Lewin, founder of group dynamics in social psychology, found that there are systems based around any individual that give rise to tensions between individuals. ${ }^{2}$ These tensions operate like electrostatic fields and interact, resulting in behaviour (as people sense and perceive, and then construe ${ }^{3}$ ) that reorganises the tension system. The occurrence of "problem behaviours" might be seen as the end result of a system reorganising in such a way as to "force" a "leak" of behaviour at the point of least resistance.

The Finnish neuropsychologist Timo Järvilehto seems to support this idea from a social neuropsychological viewpoint. ${ }^{4}$ His work accentuates the existing neurobiological substrate that can be said to underlie any person's behaviour but that none the less cannot possibly be the sole cause of that behaviour.

We cannot assume that autism is an "illness" with the same types of aetiological factors seen in, for example, haemorrhoids. Autism is best seen as a continual set of possible response states by the individual, concerned with inhospitable situational factors with which he or she has to deal. It is the best possible defensive response by the autistic person to the expectations and attitudes of the society into which he or she has been born. An autistic person may behave totally differently in any two different situations, which seems to support the notion of tension systems in that person's system that encompass organism and environment. ${ }^{5}$

I believe that biological causes for autism cannot be found, regardless of contributory factors. For this reason, I find the whole vaccine debate tiresome. The research should be oriented to discovering the types of interactions between the person and his or her environment are that bring about autistic states. Trying to find a biological cause for autism is akin to attempting to find a psychological basis for piles.

David N Andrews psychologist in training Satamakatu 15 B 15, 48100 Kotka, Finland

1 Dyer O. Experts question latest MMR research. BMJ 2002:325:354. (17 August)

2 Fontana D. Personality in the workplace. New York: Palgrave Macmillan, 2000.

3 Boeree CG. Personality theories: George Kelly 1905-1967. Shippensburg, PA: Shippensburg University, 1997. www. ship.edu/ cgboeree/kelly.html (accessed 13 August 2002).

Responses of three health professional groups to letter from mother asking for advice about vaccinating 1 year old child against measles, mumps, and rubella

\begin{tabular}{lcccc} 
Professional group & $\begin{array}{c}\text { Response rate } \\
(\%(\text { No) })\end{array}$ & $\begin{array}{c}\text { Withdrawal rate } \\
(\%(\text { No) })\end{array}$ & $\begin{array}{c}\text { No (\%) advising } \\
\text { immunisation* }^{*}\end{array}$ & $\begin{array}{c}\text { No (\%) advising against } \\
\text { immunisation* }^{*}\end{array}$ \\
\hline Homoeopaths $(\mathrm{n}=168)$ & $72(104)$ & $26(27)$ & $2 / 77(3)$ & $31 / 77(40)$ \\
\hline Chiropractors $(\mathrm{n}=63)$ & $44(22)$ & $27(6)$ & $4 / 16(25)$ & $3 / 16(19)$ \\
\hline General practitioners & 0 & NA & NA & NA
\end{tabular}

$$
\mathrm{n}=111 \text { ) }
$$

*Directly or indirectly (of those who responded and did not withdraw). NA=not applicable. 
4 Järvilehto T. The theory of organism-environment system, parts I to IV. wwwedu.oulu.fi/homepage/tjarvile/ indexe.htm (accessed 13 August 2002). (English adaptation of the author's earlier book Ihminen ja Ihmisen Ympäristö, 1994.

5 Andrews DN. Neurological aspects of the higherfunctioning autisms (2001). http://edtech.oulu.fi/sampo/ 00-01/cumu/dna/nahfa.htm (accessed 13 August 2002).

\section{Systematic review of cost effectiveness in telemedicine}

\section{Quality of cost effectiveness studies in systematic reviews is problematic}

EDITOR-Witten et al reviewed the cost effectiveness of telemedicine. ${ }^{1}$ In their response on bmj.com they confuse the evaluation of quality with levels of evidence and study design. Quality should not be judged on levels (strength) of evidence or whether health consequences were measured but on how well these were undertaken and reported. ${ }^{3}$

Additionally, studies were rated on the "presence of a clear hypothesis." Although essential for assessing efficacy, this is less important for economic evaluations. Hypotheses require statistical testing to acceptance or rejection of the null hypothesis; economic evaluations typically use point estimates and, without variance, cannot be subjected to statistical testing. Hence, sensitivity analyses are required for testing the robustness of results. A clear statement of aims is required, and as noted by Witten et al, most economic evaluations do clearly state the aims.

Economic evaluations of telemedicine often concentrate on costs and cost minimisation, assuming health outcomes are at least as good as those from conventional services. For example, in teleradiology a reasonable assumption is that patient outcomes will be equivalent to or better (such as in terms of quicker results and avoiding travel) than conventional reporting by a radiologist. This is the conservative approach; if benefits were measured and valued the cost effectiveness of telemedicine might only appear better. Cost neutrality, used in cost analyses and cost minimisation analyses, suggests that telemedicine provides the same health outcomes without additional costs. Cost effectiveness is concerned with additional costs for additional units of benefit; it requires a value judgment about whether additional spending to obtain additional benefits is worth while.

I was disappointed that the authors did not report circumstances where telemedicine was and was not cost effective. For example, live consultations are resource and cost intensive compared with asynchronous consultations, but occasionally-for example, the highlands and islands teledentistry project ${ }^{4}-$ might be cost effective. Likewise, telemedicine might be cost effective for some disciplines such as dermatology and radiology but not for others.

In the critique of the generalisability of results, equity issues of access to healthcare services were overlooked. Many communities in the United Kingdom have barriers in accessing common healthcare services. For example, the referral rate for restorative dental consultations from the Shetland Islands (requiring travel to Aberdeen) is a 10th of that of the Orkney Islands, where a consultant visits for 1-2 days each year. ${ }^{4}$ Teledentistry and other telemedicine interventions, even with additional costs, help address inequities in access to healthcare services.

Paul Scuffham senior research fellow

York Health Economics Consortium, University of York, York YO10 5NH pas8@york.ac.uk

1 Whitten PS, Mair FS, Haycox A, May CR, Williams TL Hellmich S. Systematic review of cost effectiveness studie of telemedicine interventions. BMJ 2002;324:1434-7. (15 June.)

2 Haycox AR. Re: Economic evaluation is a broad church. bmj.com 2002. bmj.com/cgi/eletters/324/7351/1434\# 23142 (accessed 19 August 2002).

3 NHS Centre for Reviews and Dissemination. Undertakin systematic reviews of research on effectiveness. 2nd ed. York: University of York, 2001. (CRD report No 4.)

4 Scuftham P. Steed M. An economic evaluation of the highlands and islands teledentistry project J Telemed Tloca 2002:8:165-77.

\section{Authors' reply}

EDITOR-We did not try to introduce new evidence on telemedicine in our review but simply considered evidence already in existence. We emphasise that a lack of evidence for the cost effectiveness of telemedicine does not imply evidence of a lack of cost effectiveness for telemedicine. Our review identified the former without contributing towards the debate on the latter.

One weakness of the evidence base was its inability to identify circumstances where telemedicine was or was not cost effective. Perhaps more than in any other area of new technology, the cost effectiveness of telemedicine is location specific. This is not to say that results obtained in one location the highlands of Scotland) cannot be generalised to other locations (the centre of Liverpool) but that such generalisation must be undertaken with the utmost care.

Specifically, an impact model should be developed to distinguish between elements that contribute to the success of a telemedicine service and can be generalised throughout the NHS-for example, technological factors-and those that are location specificfor example, geographical and environmental factors. Often, the success of a telemedicine service evaluated in inaccessible locations has been automatically assumed to be generalisable elsewhere, with no attempt being made to test this assumption. Our review presents a challenge to the telemedicine research community to strengthen its analyses by identifying the extent to which results obtained in one research location are likely to be replicable elsewhere.

Our review is also an early overview of the quality of research currently available in telemedicine. Although it is timely, given the growing interest in this branch of medicine, we also acknowledge that we reviewed a technology in its early stage of development. We would thus welcome the opportunity to revisit our review, hopefully to reflect an evidence base that has been enhanced in response to the challenges we have presented. We are generally persuaded of the potential value of telemedicine, but our role in undertaking the review was not to be for or against telemedicine but simply to reflect the quality of the current evidence base. We hope we have highlighted some of the areas in which the quality of this evidence base can be improved.

A R Haycox senior lecturer-health economics

F S Mair senior lecturer-primary care

University of Liverpool, Liverpool L69 3GE

\section{Brain death}

\section{Brain death is a recent invention}

EDITOR-Your explicit recognition that "brain death" is a recent invention for transplant purposes is most welcome and should do much to expose the fallacies and fudgings associated with this supposed new form of death, which have been hidden from public and professional view for far too long. ${ }^{1}$ As one of those described as campaigning tirelessly against the concept and the bad science underpinning its diagnosis, I am grateful for your journal's support. I query your statement, however, that most doctors in Britain are comfortable with the concept of brain death. Is that statement evidence based? Or is it more likely that most doctors have no need to think deeply about this matter-and choose not to do so?

The review to which you refer notes the cultural emphasis of Margaret Lock's study. ${ }^{2}$ More detailed consideration of the philosophical and scientific aspects will be found in the anthology by Potts et al, which was not available to Lock when she was writing." Since then, thanks to the excellent rapid response facility provided by bmj.com, the most significant development has been the wide dissemination of knowledge about the dangers of the apnoea test (which is a crucial element in the schedule of tests laid down by the Department of Health for the diagnosis of "brain stem death" or "death for transplant purposes"). Thanks, particularly, to the work of Coimbra, it is now clear that apnoea testing may exacerbate the brain damage and even prove lethal. ${ }^{4}$ That being so, and bearing in mind that the test can be of no possible therapeutic benefit to the patient so tested, its use is clearly unethical.

How long, therefore, now that this risk is generally known, can the Department of Health go on encouraging use of this damaging diagnostic procedure-which may have ensured the fulfilment of the allegedly invariably fatal prognosis attached to the diagnosis of "brain stem death" in at least some cases in the past?

David W Evans retired physician Cambridge CB3 9LN

DWEvansMD@tinyworld.co.uk

1 Editor's choice. Deep fears. BMJ 2002;324(7348). (8 June.) 2 Gray C. "Twice dead: organ transplants and the reinvention of death" by Margaret Lock [reviewed]. BMJ 2002;324:1401

3 Potts M, Byrne PA, Nilges R, eds. Beyond brain death-the case against brain based criteria for human death. Dordrech Kluwer, 2000.

4 Coimbra CG. Implications of ischemic penumbra for the diagnosis of brain death. Braz J Med Biol Res 1999;32: 1479-87. 


\section{Fear has basis in reason}

EDITOR-A deep seated fear may yet be rational. The fear of being declared dead while still alive, in the case of "brain dead" patients, is a fear with a basis in reason. ${ }^{1}$ If such patients are not dead, they certainly will be after unpaired vital organs are removed for transplantation. Rather than being "settled," the acceptability of criteria for brain death is the subject of intense international debate.

As early as 1974, the philosopher Hans Jonas wrote in opposition to brain death criteria ${ }^{2}$; a lengthy article by Byrne et al followed nine years later (reprinted in an anthology by Potts et $\mathrm{al}^{3}$ ). More recently, the neurologist Alan Shewmon reversed his previous support for brain death criteria. ${ }^{4}$ In 2000, the anthology Beyond Brain Death was published, with contributors from the United States, the United Kingdom, Japan, and Liechtenstein.

There are many reasons for this growing opposition. Shewmon's accounts of long term survivors of whole brain death empirically falsify the claim that whole brain death marks the end of a unified human organism. ${ }^{4}$ Even if Shewmon's claims are unfounded, a prognosis that brain death will lead to immanent somatic death (in the sense of the loss of a unified functioning organism) is not the same thing as a diagnosis that somatic death has occurred (Byrne et $\mathrm{al}^{3}$ ). Evans, among others, discusses the mounting evidence that brain activity persists in a number of patients declared brain dead. ${ }^{3}$ Coimbra identifies the dangers in a key test used to diagnose brain death, the apnoea test. ${ }^{5}$ Philosophers, such as Hans Jonas and Josef Seifert, have attacked the dualism of brain and body (Jonas' term) that is inherent in criteria for brain death. ${ }^{3}{ }^{3}$

This debate should raise serious doubts concerning whether brain dead people are dead and lead to a rethinking of the entire enterprise of removing vital organs from such patients. A fundamental goal of medicine is to do no harm (non-maleficence). Any action that directly causes the death of a patient, even if it is for the good of others, opposes the goal of medicine not to harm that individual patient. Any attempt to downplay the importance of the brain death debate in the interests of organ transplantation is therefore fundamentally wrong. It is precisely whether transplantation kills the donor that is the key issue that cuts to the heart of the goals of medicine.

Michael Potts head

Philosophy and Religion Department, Methodist College, 5400 Ramsey Street, Fayetteville, NC 28311-1420, USA

mpotts20@hotmail.com

1 Editor's choice. Deep fears. BMJ 2002;324(7348). (8 June.) 2 Jonas H. Against the stream. In: Philosophical essays: from ancient creed to technological man. Englewood Cliffs, NJ Prentice-Hall, 1974.

3 Potts M, Byrne PA, Nilges RG, eds. Beyond brain death: the case against brain based criteria for human death. Dordrecht: Kluwer, 2000.

4 Shewmon DA. "Brain stem death," "brain death" and death: a critical reevaluation of the purported evidence. Issues Law Med 1998;14:125-45.

5 Coimbra CG. Implications of ischemic penumbra for the diagnosis of brain death. Braz J Med Bio Res 1999;32: 1479-87.

\section{Staphylococci may indeed cause acute dental infections}

Editor-In their letter Ribeiro and Cousin contend the likelihood of a causal relation between the development of an epidural abscess after root canal treatment and the isolation of Staphylococcus aureus in the report by O'Rourke et al. ${ }^{12}$

We disagree and support the original proposal of O'Rourke et al because recent studies using both molecular technology and conventional culture techniques indicate conclusively that Staphylococcus spp are not uncommon in dental root canal infections. ${ }^{3}$ Furthermore, in a stringent and comprehensive investigation that we are currently conducting on the microflora of endodontically involved teeth, staphylococci were isolated from root canals in eight out of 86 patients (unpublished data). Indeed in two cases, staphylococci were the sole and major isolate from the aseptically opened, infected root canals.

We emphasise, however, that most endodontic infections are polymicrobial in nature. Using the polymerase chain reaction, Munson et al recently found a mean of 17 taxa in endodontic samples and a total of 30 new phylotypes. ${ }^{5}$ Therefore, acute dental infections are still best treated by antimicrobial agents such as penicillin, amoxicillin, clindamycin, and metronidazole, but the possibility of staphylococci causing acute exacerbations or bacteraemias should not be overlooked

Peter C S Tsang clinical assistant professor Federick C. S Chu clinical assistant professor Lakshman P Samaranayake professor of oral microbiology

Faculty of Dentistry, University of Hong Kong, 34 Hospital Road, Hong Kong, China csptsang@hku.hk

1 Ribeiro N, Cousin G. Staphylococci are unlikely to cause acute dental infections. BMJ 2002;324:1457. (15 June.)

2 O'Rourke F, Barker R, Khan S. Minerva. $B M$ 2002;324:686. (16 March.)

3 Kitaura H, Ohara N, Matsuo T, Kobayashi K, Yamada T PCR amplication of $16 \mathrm{~S}$ ribosomal RNA gene for detection of bacterial infection in root canal. Dent Jap detection of bact $1997 \cdot 34 \cdot 21-3$. 4 Gomes BPFA, Lilley JD, Drucker DB. Clinical signific of dental root canal microflora. J Dent 1996;24:47-55. 5 Munson MA, Pitt Ford T, Mcnish A, Chong B, Weightman AJ, Wade WG. Molecular analysis of microflora associated with endodontic infections.J Dent Res 2001;80:767.

\section{Children are still seen but not heard}

EDITOR-Kroenke and Gask and Underwood describe in some detail the multiplicity of psychological presentations in patients. ${ }^{12}$ No mention is made, however, of the many children seen in general practice and by paediatricians who have primarily mental health problems, psychological factors associated with their physical illness (such as diabetes management), or medically unexplained symptoms (such as recurrent abdominal pain). The best estimate of the prevalence of psychiatric disorders in young people in the United Kingdom is the Office for National Statistics figure of $10 \%$ of all children. ${ }^{3}$ This figure increases appreciably in inner cities and when chronic ill health, and particularly neurological disorders, are present. But only one in five of these attend mental health services for children and adolescents. Some evidence exists that family doctors can provide effective treatment for this group. ${ }^{4}$

Children are in the unique position of being presented to their family doctors by parents, rather than seeking help themselves. They are therefore vulnerable in "the consultation" to the effects of mental illness and personality disturbance in their parents, which can range from the genuinely (over-) anxious to the homicidal.

Quite apart from the genetic transmission, the psychosocial impact of parental mental illness, separation, and divorce is considerable and may well present as psychosomatic symptoms in vulnerable children. At the other end of the scale, a few parents and carers actively harm children and then seek help for their illness.

Patterns of help seeking behaviour are established in childhood. Practising psychological medicine in children may well reduce undesirable adult patterns of health care use. If it is to truly encompass the whole person, child and adult, psychological medicine must consider all members of the family, not only adult patients.

Sean P Maskey consultant child and adolescent

psychiatrist

Great Ormond Street Hospital, London

WC1N 3JH

maskes@gosh.nhs.uk

\begin{abstract}
1 Kroenke K. Psychological medicine. BMJ 2002;324: 1536-7.

2 Gask L, Usherwood T. ABC of psychological medicine: the consultation. BMJ 2002;324:1567-9.

3 Meltzer H. Mental health of children and adolescents in Great Britain. London: Stationery Office, 2000.

4 Bower P, Garralda E, Kramer T, Harrington R, Sibbald B. The treatment of child and adolescent mental health problems in primary care: a systematic review. Fam Pract 2001;18:373-82.
\end{abstract}

\section{Recommendations from quality of life scales are not simple}

EDITOR-As someone who is guilty of adding to the large number of disease specific quality of life (QOL) scales, let me add a note of caution to the pleas made by Garratt et al for guidance and recommendations for the users of these scales-however understandable that plea is. ${ }^{1}$ QOL scales are not like thermometers or spirometers, where the reading is independent of the type of patient.

A QOL scale is just a shopping bag of experiences (or questions) that are put together to form a scale, rather like the retail price index. The retail price index is a shopping bag of goods for an "average" shopper, even though most people are not that average shopper. The scale value obtained from a QOL scale depends on the overlap between the items in a scale and the patient's own experience of disease. So, for example, if there is a generic QOL scale and there are many pain items but no items on sleep disturbance, then arthritis will come out worse than asthma. The same logic applies to disease specific scales. If there are 
questions about sport, and most patients are elderly, then there is little complaint about how health has affected their sporting life.

It is the nature of QOL assessment that the "best" scale is always best for a particular purpose, where purpose is defined in terms of disease, population, and treatment. An example will illustrate this. We developed a scale to measure QOL in patients with chronic obstructive pulmonary disease (COPD), which was subsequently used to assess improvement after rehabilitation. ${ }^{2}$ Some of the items measuring COPD severity did not change- they were indicators of severity that were encouraged by rehabilitation (for example, using pillows at night; eating regular, smaller meals). Subsequently, we developed a scale for evaluating rehabilitation by selecting items that showed change after rehabilitation. ${ }^{3}$ In other words, we selected the items from our big trolley to make a smaller basket that measured what we wanted. QOL scale selection is a matter of selecting baskets of items that match a particular purpose.

A final warning: QOL researchers always recommend their own scales. It is a personal thing - to the author, the scale is a bit like his or her child. The more "successful" scales tend to be those whose authors are better promoters. The last person you should come to for a recommendation about QOL scales is someone who is an author-including myself.

Michael E Hyland professor of health psychology University of Plymouth, Plymouth PL4 8AA mhyland@plymouth.ac.uk

1 Garratt A, Schmedit L, Mackintosh A, Fitzpatrick Quality of life measurement: bibliographic study of patient assessed health outcome measures. BMJ 2002;324:1417-9. (15 June.)

2 Hyland ME, Bott J, Singh S, Kenyon CA P. Domains, constructs, and the development of the breathing problems questionnaire. Oual Life Res 1994:3:245-56.

3 Hyland ME, Singh SJ, Sodergren SC, Morgan MDL. Development of a shortened version of the Breathing Problems Questionnaire suitable for use in a pulmonary rehabilitation clinic: a purpose-specific, disease-specific questionnaire. Qual Life Res 1998;7:227-33.

\section{Parents are an untapped resource in sex education}

EDITOR-It is almost 20 years since Victoria Gillick tried to force doctors to obtain parental consent before treating children. Paradoxically her legacy was to remove any parental role in the provision of contraception for young people.

Britain now has the highest teenage pregnancy rate in Europe and the second highest in the world. Government led attempts to reduce it have focused on endless teenage initiatives, providing ready access to free contraception and advice. ${ }^{1}$ The latest announcement of free condoms available through schools is another variation on the same theme and will surely contribute insignificantly.2 In a study in Nottingham many teenagers who became pregnant had sought contraceptive services in the preceding 12 months. ${ }^{3}$ Hence, contraceptive failure is as significant a factor as simple access to contraception.
A sea change in parental attitude has occurred in the last generation: a whole generation of parents has become tolerant about the depiction of sexual intercourse on television, hearing jokes about drugs, and the concept of teenagers experimenting with sex. They represent a huge and currently untapped resource that could help in guiding teenagers about contraception.

Parents are informed that their child is having sex education in school, but they are not actively invited to participate in this process. Parents would benefit from knowing that talking about sexual intercourse does not encourage teenagers to experiment at an earlier age. Young people who use contraception are likely to use it more effectively if their parents are aware that they are using it. Teenagers will benefit from knowing their parents' specific view about their personal use of contraception, rather than a general discussion of the birds and the bees. Many teenagers might be relieved to find their parents open minded and sensible, underneath the British "stiff upper lip" exterior-if both parties were better able to communicate their views.

Setting out a programme to help parents clearly convey their views and, hopefully, give their teenager parental permission to use contraception (and possibly practical help in obtaining it) may sound old fashioned, but at least it merits piloting and could be an additional strategy to those currently planned.

Rachel G Pryke general practitioner Winyates Health Centre, Redditch B98 0NR drpryke@inglewood.fsnet.co.uk

\section{Wight D, Raab G, Henderson M, Abraham C, Buston K, Hart G, et al. Limits of teacher delivered sex education interim behavioural outcomes from randomised trial. $B M J$ 2002:24:1430-3. (15 June.) \\ 2 Kirby D, Resnick MD, Downes B, et al. The effects of school-based health clinics in St Paul on school-wide birthrates. Fam Plan Perspect 1993;25:12-6. \\ 3 Churchill D, Allen J, Pringle M, Hippisley-Cox J, Ebdon D, Macpherson M, et al. Consultation patterns and provision of contraception in general practice before teenage pregnancy: case-control study. $B M J$ 2000;321:486-9.}

\section{Mobile phone text messaging can help young people manage asthma}

EDITOR-The main reason why asthma is suboptimally controlled in many young people is that the medicine (inhaled drugs) and the message (education) do not reach their intended target-the lung and the brain. Doctors try to make young people comply with treatment while young people try to make the disease comply with their lifestyle. ${ }^{12}$

We set up a mobile phone text message service consisting of daily reminders to use an inhaler, health education tips, and safety messages. We streamed these into a supply of lifestyle related text messages about sport, celebrity gossip, and horoscopes; they were all written in contemporary text jargon and sent by a "virtual friend with asthma" called Max. Thirty two young people with asthma from Tayside, Scotland, were recruited through local radio to take part in a study to

\section{Some text message dialogues}

"Bonjour, c'est Max. Hav U taken Ur inhaler yet?"

"Yea, I'm off to take it now" (Kim)

"Buenas noches. Max here. Forgotten something 2day?"

"Beat U 2 it. Just tkn it!" (Laura)

"Yo dude, its Max reminding U2 takeur inhaler"

"Yep dis mornin" (Alex)

Improved compliance

"I used to forget [my inhaler] two or three times each week ... I haven't missed once this month" (Kevin)

assess the safety, reliability, acceptability, and effectiveness of the service. The study was approved by an ethics committee.

We ran focus groups before and after the study and tracked all text messages sent and received by our participants (age range 10 to 46 , median 16) over one month. There were no adverse safety events, and the service was technically reliable.

The 30 participants who completed the service thought that the tone and style of the text messages and the medium were credible. They commended us for basing the service around novelty lifestyle text messages with the optional provision of medical facts and reminders available on request. Participants seemed to develop a rapport with their virtual friend with asthma and frequently sent text messages back to Max. Compliance with using an inhaler may have favourably changed in response to the service (box).

Text messages that are reminders about treatment and useful tips on education may be a medium to allow people with chronic health problems to make their disease comply with their lifestyle and not the other way around.

Ron Neville general practitioner

Westgate Health Centre, Dundee DD2 4AD r.g.neville@dundee.ac.uk

Alexandra Greene lecturer in social anthropology Department of Social Anthropology, University of St Andrews, St Andrews, Fife KY16 9AL

John McLeod professor of counselling

Department of Social and Health Sciences,

University of Abertay, Dundee DD1 1HG

Andrew Tracy project manager

John Surie director

Wonderworks (Communication Consultancy),

London NW1 8JD

1 Neville RG, McCowan C,Hoskins G, Thomas G. Cross sectional observations on the natural history of asthma. $\mathrm{Br} \mathrm{I}$ Gen Pract 2001:51:361-5.

2 Donovan JL, Blake DR. Patient compliance: deviance or reasoned decision making? Soc Sci Med 1992;34:507-13.

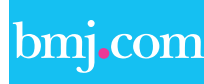

\section{Rapid responses}

Correspondence submitted electronically is available on our website 